\title{
Effect of Resiniferatoxin as an Anti-Inflammatory Drug on Experimental Trichinellosis
}

\author{
Doaa A.A. Balaha ${ }^{1 *}$, Howaida I. H. Ismail ${ }^{1}$, \\ Omnia M. K. Risk ${ }^{2}$ and Ghada A. M. Gamea ${ }^{1}$ \\ ${ }^{1}$ Department of Medical Parasitology, Faculty of Medicine, Tanta University, Tanta, Egypt \\ ${ }^{2}$ Department of Pathology, Faculty of Medicine, Tanta University, Tanta, Egypt \\ Tanta University, Tanta, Egypt \\ *Corresponding author
}

\section{A B S T R A C T}

\section{Keywords}

Trichinella spiralis, Resiniferatoxin,

Cortisone,

Inflammation, IFN$\gamma$ and iNOS

Article Info

Accepted:

22 June 2020

Available Online:

10 July 2020
Trichinellosis is a parasitic disease causing a harmful inflammatory response. Corticosteroids are used as anti-inflammatory drugs but cause immunesuppression. The present study evaluated the anti-inflammatory effect of resiniferatoxin (RTX), a TRPV1 receptor agonist as an adjuvant therapy with albendazoleon the early and late stages of experimental trichinellosis in comparison with cortisone. The effect of RTX was evaluated by determination of the total larval count in the skeletal muscles, degree of inflammation in intestine and muscles and and the determination of the serum level of interferon gamma (IFN- $\gamma$ ) and inducible nitric oxide synthase (iNOS) by ELISA. Our results showed that treatment with (albendazole and RTX) significantly decreased the total larval count and the inflammation in both the intestinal and the musclar phases in comparison with other groups. In addition, RTX decreased the serum levels of IFN- $\gamma$ and iNOS. We concluded that RTX has valuable anti-inflammatory and immuno-modulatory effects against $T$. spiralis infection and is beneficial for the treatment of trichinellosis as compared to cortisone.

\section{Introduction}

Trichinellosis is a parasitic disease caused by T. spiralis which is the most common species of Trichinella infection all over the world. The infection is caused by ingestion of raw or undercooked meat containing the encysted larvae and has both enteral and parental phases (Sofronic-Milosavljevic et al., 2017). $T$. spiralis infection induces an intense inflammatory response in the small intestine. It destroys the epithelial cells it occupies. The inflammatory response caused by the invasion of muscles by the migrating larvae leads to damage of the muscle cells and loss of the myofibrils (Wu et al., 2012). 
Albendazole is a benzimidazole drug that has a worldwide usage against multiple helminthic infections including Trichinella. The T-cell immune response can be modulated by its stimulatory action on enzymes and mediators as glutathione transferase and iNOS during Trichinella infection (Shalaby et al., 2010).

The anti-inflammatory treatment during trichinellosis includes steroids; but their side effects limit their usage as they mainly suppress the immune response increasing the parasite burden and its survival in the host tissue (Piekarska et al., 2010). The immune response against $T$. spiralis at the intestinal phase depends on the T-helper cells (Th). Stimulation of Th cells includes both Th1 and Th2 with initial predominance of the Th1 type and consequent response of $\mathrm{Th} 2$ in order to achieve protection and parasite expulsion (Ilic et al., 2012).

This process is characterized by secretion of cytokines such as interleukin IL4, IL5, IL10 and IL13, as well as immunoglobulin E (Bruschi and Chiumiento, 2012). The activity of IL4 and IL13 causes release of tumour necrosis factor $\alpha$ (TNF- $\alpha$ ) and INF- $\gamma$, by the activation of intestinal mucosal mast cells resulting in local inflammation (Akiho et al., 2011). Release of TNF- $\alpha$ leads to stimulation of iNOS, resulting in the production of nitric oxide (NO) which has an effect against both extracellular and intracellular parasites. The inflammatory response caused by TNF- $\alpha$ and NO enhances the development of enteropathy by $T$. spiralis (Wink et al., 2010). Therefore, there is a great need for a new drug that improves the host defense mechanism against trichinellosis. Resiniferatoxin (RTX) is derived from a cactus-like plant named Euphorbia resinifera. Most of the biological actions of RTX are mediated by the transient receptor potential vanilloid 1 (TRPV1) by intial desensitizing then blocking these receptors leading to its analgesic effect
(Nilius and Szallasi, 2014). It also has a potent anti-inflammatory effect by reducing the expression of iNOS leading to decrease NO serum level (Chen et al., 2003). So there is a great need to evaluate the therapeutic effect of RTX on the inflammatory response against $T$. spiralis infection. The aim of the present study was to evaluate the antiinflammatory effect of RTXas an adjuvant therapy with albendazole on the early and late stages of experimental $T$. spiralis infection as a model of an intestinal and tissue parasite.

\section{Materials and Methods}

\section{Parasite}

The strain of $T$. spiralis was obtained from infected albino mice in the Medical Parasitology Department Laboratory, Tanta University. This research was approved by the research ethical committee, Faculty of Medicine, Tanta University and its approval code is $32284 / 04 / 18$.

For this purpose 120 Swiss albino mice were classified into five main groups.

Group (I) represented the negative control. Group II represented the positive control which was further subdivided into two subgroups: subgroup (IIa) was sacrificed on day 6 p.i. and subgroup (IIb) was sacrificed on day 35 p.i.. Group III represented the infected mice that were treated with albendazole only. This group was further subdivided into three subgroups as follows: subgroup (IIIa) starting treatment on day 3 p.i. (early treatment) and was sacrificed on day 6 p.i., subgroup (IIIb) starting treatment on day 3 p.i. (early treatment) and was sacrificed on day 35 p.i. and subgroup (IIIc) starting treatment on day 21 p.i. (late treatment) and was sacrificed on day 35 p.i. Group IV represented the infected mice that were treated with both (albendazole and RTX). Group V represented the infected mice that 
were treated with both (albendazole and dexamethasone (Dexa)). Both groups IV and $\mathrm{V}$ were subdivided as group III.

\section{Drugs}

\section{Albendazole}

A commercial preparation of the drug, alzental suspension (EIPICO) with a concentration of $20 \mathrm{mg} / \mathrm{ml}$ was used. The drug was given by intra-esophageal gavage to each mouse in a dose of $50 \mathrm{mg} / \mathrm{kg}$ body weight/day for 3 successive days starting on day 3 p.i for early treated subgroups and on day 21 p.i for late treated subgroups (Li et al., 2012).

\section{Resiniferatoxin (RTX)}

A raw material of the drug, resiniferatoxin powder (TOCRIS) weighing $1 \mathrm{mg}$ was used. The drug was administered intra-peritoneally in a dose of $20 \mu \mathrm{g} / \mathrm{kg}$ on days 3 and 5 p.i. for early treated subgroups and on days 21 and 23 p.i. for late treated subgroups (Ueda et al., 2008).

\section{Steroids}

A commercial preparation of the drug, dexamethasone sodium phosphate ampoule (Dexa) (AMRIYA) with a concentration of $8 \mathrm{mg} / 2 \mathrm{ml}$ was used. The drug was administered intra-peritoneally in a dose of 1 $\mathrm{mg} / \mathrm{kg}$ on days 3 and 5 p.i. for early treated subgroups and on days 21 and 23 p.i. for late treated subgroups (Sun et al., 2012).

\section{Mice were subjected to the following}

\section{Parasitological study}

Total larval count (TLC) in the skeletal muscles (Wranicz et al., 1998)

On day 35 p.i., five mice from all groups were euthanized. Muscle samples were obtained from the thigh and kept in $10 \%$ formalin for histopathological examination. The rest of the skeletal muscles were used for TLC.

\section{Histopathological study}

\section{Histopathological examination of the small intestine and the muscle specimens}

Intestinal specimens $(1 \mathrm{~cm}$ from the small intestine) were taken from the mice sacrificed on day 6 p.i. (Nassef et al., 2010). Skeletal muscle specimens from the thighs were taken from the mice sacrificed on day 35 p.i. (Monib et al., 2010).

\section{Inflammatory scoring}

In order to score the degree of intestinal inflammatory infiltrate, the inflammatory reaction was assessed in the intestinal sections using semi-quantitative score of the inflammation. For muscle specimens, the intensity of the inflammatory reaction around the encapsulated larvae was evaluated by using the inflammatory score. This score was represented as mild $<2$, moderate $<4$ and severe $>4$ (El-Kowrany et al., 2019).

\section{Immunological study}

Determination of the serum level of mouse interferon $\gamma($ IFN- $\gamma$ ) and mouse inducible nitric oxide synthase (iNOS) was done by enzyme-linked immune-sorbent assay technology (ELISA) on day 6 p.i. for the early treated subgroups (subgroups a) and on day 25p.i. for the late treated subgroups (subgroups c) and their controls.

\section{Statistical analysis}

Statistical presentation and analysis of the present study was conducted, using the mean, standard deviation (SD) and chi-square test by SPSS V.22. Significance was determined by a one way analysis of variance (ANOVA) (f 
test) for comparison between more than two means in quantitative data. A $\mathrm{P}$ value $<0.05$ was considered statistically significant. A P value $<0.01$ was considered statistically highly significant.

\section{Results and Discussion}

\section{Parasitological study}

Total larval count (TLC) of $T$. spiralis in the muscles was performed on day 35 p.i. for all subgroups (b)

The mean TLC in the infected non-treated mice (subgroup IIb) was $20000 \pm 3807.89$. In relation to the infected non-treated mice (subgroup IIb), there was a highly significant decrease in the mean TLC of the infected mice treated with albendazole (subgroup IIIb) reaching $500 \pm 136.93(\mathrm{P}=0.001)$ with $97.5 \%$ reduction. Also, there was a highly significant decrease in the mean TLC in the infected mice treated with albendazole and RTX (subgroup IVb) to be $200 \pm 48.99(\mathrm{P}=0.001)$ with $99 \%$ reduction. In the infected mice treated with albendazole and Dexa (subgroup $\mathrm{Vb}$ ), the mean TLC showed a highly significant decrease in relation to infected non-treated mice (subgroup IIb) reaching $1000 \pm 158.11(\mathrm{P}=0.001)$ with $95 \%$ reduction. There was a highly significant difference between subgroup IIIb (treated with albendazole) and subgroup IVb (treated with albendazole and RTX) $(\mathrm{P}=0.002)$. Also, there was a highly significant difference between subgroup $\mathrm{IIIb}$ and subgroup $\mathrm{Vb}$ (treated with albendazole and Dexa) $(\mathrm{P}=$ 0.001) and subgroup IVb and subgroup Vb (P $=0.001)($ Fig. 1a).

TLC of $T$. spiralis was performed on day 35 p.i. for all subgroups (c)

In relation to the infected non-treated mice (subgroup IIb), there was a highly significant decrease in the mean TLC of the infected mice treated with albendazole (subgroup IIIc) reaching $9000 \pm 1457.74(\mathrm{P}=0.001)$ with $55 \%$ reduction. Also, there was a highly significant decrease in the mean TLC of the infected mice treated with albendazole and RTX (subgroup IVc) reaching $7200 \pm$ 972.11( $\mathrm{P}=0.001)$ with $64 \%$ reduction. There was an insignificant difference between subgroup IIIc and subgroup IVc $(\mathrm{P}=0.051)$.

In the infected mice treated with albendazole and Dexa (subgroup Vc), there was a highly significant decrease in the mean TLC in relation to the infected non-treated mice (subgroup IIb) reaching $8000 \pm 1369.31(\mathrm{P}=$ 0.001 ) with $60 \%$ reduction. But there was an insignificant difference between both subgroup III c (treated with albendazole) and subgroup Vc $(\mathrm{P}=0.296)$ and between subgroup IVc (treated with albendazole and RTX) and subgroup Vc $(\mathrm{P}=0.318)$ (Fig.1b).

\section{Histopathological study with inflammatory scoring}

\section{Small intestinal findings}

Small intestinal sections of $T$. spiralis infected non-treated mice (subgroup IIa) 6 days p.i. revealed edema and elongation of the villous core with severe inflammatory cellular infiltrate giving a mean inflammatory score of $5.40 \pm 0.55$. The infiltrate was in the form of lymphocytes, eosinophils and neutrophils (Fig.3a). In addition, there was goblet cell hyperplasia with high mitotic activity (Fig. 3b). Small intestinal section of $T$. spiralis infected mice treated with albendazole (subgroup IIIa) 6 days p.i. revealed moderately elongated villi, moderate edema and inflammatory cellular infiltrate with a mean inflammatory score of $3.20 \pm 0.84(\mathrm{P}=$ 0.001) (Fig. 4a). However, in the infected mice treated with albendazole and RTX (subgroup IVa) there was mild inflammation 
and in some there was almost normal intestinal epithelium with a mean inflammatory score of $0.80 \pm 0.45(\mathrm{P}=0.001)$ (Fig. 4b).The infected mice treated with albendazole and Dexa (subgroup $\mathrm{Va}$ ) revealed mild inflammatory cellular infiltrate with lymphoid hyperplasia, shortening of the villi and mild edema with a mean inflammatory score of $1.40 \pm 0.55(\mathrm{P}=0.001)$ (Fig. 4c). There was a highly significant difference between group III and IV $(\mathrm{P}=0.001)$. However, there was insignificant difference between group IV and V (P=0.094) (Fig.2a).

\section{Skeletal muscle findings}

Muscle sections of $T$. spiralis infected nontreated mice (subgroup IIb) 35 days p.i. revealed multiple encapsulated larvae surrounded by severe inflammatory cellular infiltrate giving a mean inflammatory score of $5.60 \pm 0.55$. The infiltrate was in the form of plasma cells, lymphocytes, macrophages and neutrophils (5b). There was loss of the myofibrils (Fig. 5a).

\section{Skeletal muscle findings in subgroups b (early treated)}

In the infected mice treated with albendazole (subgroup IIIb) 35 days p.i. revealed less number of the encapsulated larvae surrounded by moderate inflammatory cellular infiltrate around them with a mean inflammatory score of $2.80 \pm 0.84(\mathrm{P}=0.001)$ (Fig. 6a). In the contrary, those treated with albendazole and RTX (subgroup IVb) showed mild inflammatory cells and minimal amount of larvae, some showed absent larvae with normal striation with a mean inflammatory score of $0.80 \pm 0.84(\mathrm{P}=0.001)$ (Fig. 6b). However, in the infected mice treated with albendazole and Dexa (subgroup $\mathrm{Vb}$ ), there were nurse cells with mild to moderate inflammatory cellular infiltrate giving a mean inflammatory score of $2.40 \pm 0.89(\mathrm{P}=0.001)$
(Fig. 6c). There was a highly significant difference between group III and IV $(\mathrm{P}=$ 0.005). However, there was insignificant difference between group IV and V $(\mathrm{P}=$ 0.019) (Fig.2b).

\section{Skeletal muscle findings in subgroups c (late treated)}

Muscle section of $T$. spiralis infected mice treated with albendazole (subgroup IIIc) 35 days p.i. revealed moderate to severe inflammatory cellular infiltrate, remnants of the larva and hyaline degeneration of some nurse cells with a mean inflammatory score of $4.20 \pm 0.84(\mathrm{P}=0.008)$ (Fig. 7a). Muscle section of $T$. spiralis infected mice treated with albendazole and RTX (subgroup IVc) revealed mild to moderate inflammatory infiltrate, remnants of the larva and hyaline degeneration of the nurse cells giving a mean inflammatory score of $(1.60 \pm 0.55)(\mathrm{P}=$ 0.001) (Fig. 7b). Muscle section of $T$.spiralis infected mice treated with albendazole and Dexa (subgroup Vc) revealed encapsulated larvae with mild to moderate inflammatory cellular infiltrate and calcification giving a mean inflammatory score of $2.40 \pm 0.89(\mathrm{P}=$ 0.001) (Fig. 7c). There was a highly significant difference between group III and IV $(\mathrm{P}=$ 0.001 $)$. However, there was insignificant difference between group IV and $\mathrm{V}(\mathrm{P}=0.100)($ Fig.2c).

\section{Immunological study}

\section{Determination of the serum level of IFN- $\gamma$} by ELISA

\section{Serum levels of IFN- $\gamma$ determined on day 6 p.i. in subgroups (a)}

The mean normal level of IFN yin the noninfected non-treated mice (group I) was 4.90 \pm 1.21 . The mean serum level in the infected non-treated group (subgroup IIa) was 
significantly increased reaching $23.00 \pm 8.29$ $(\mathrm{P}=0.020)$. Compared to the infected nontreated group (subgroup IIa), there was an insignificant increase in the mean serum levels of the infected mice treated with albendazole (subgroup IIIa) reaching $27.30 \pm$ $5.69(\mathrm{P}=0.320)$. However, there was a significant decrease in the mean serum level in the infected mice treated with albendazole and RTX (subgroup IVa) reaching $9.57 \pm 2.30$ $(\mathrm{P}=0.024)$. Also, there was an insignificant decrease in the mean serum levels of the infected mice treated with albendazole and Dexa (subgroup Va) as their mean levels were $14.10 \pm 3.31(\mathrm{P}=0.175)$ respectively. In addition, there was a significant decrease in the mean serum level in subgroup IVa and subgroup $\mathrm{Va}$ in relation to subgroup IIIa $(\mathrm{P}=$ $0.002)$ and $(P=0.009)$ respectively. There was an insignificant difference in the mean serum level between subgroup IVa (treated with albendazole and RTX) and subgroup Va (treated with albendazole and Dexa) $(\mathrm{P}=$ 0.181) (Fig. 8a).

\section{Serum levels of IFN- $\gamma$ determined on day 25 p.i. in subgroups (c)}

The mean serum level in the infected nontreated group (subgroup IIb) was significantly increased as compared to the non-infected non-treated mice (group I) as their mean levels were $22.08 \pm 9.35$ and $4.90 \pm 1.21$ respectively $(\mathrm{P}=0.034)$. In relation to subgroup IIb, there was an insignificant increase in the mean serum level in the infected mice treated with albendazole (subgroup IIIc) as their mean levels were $24.47 \pm 7.83$ ( $\mathrm{P}=0.634)$. However, there was a significant decrease in the mean serum level of the infected mice treated with albendazole and RTX (subgroup IVc) reaching $10.63 \pm$ $4.10(\mathrm{P}=0.038)$. In addition, in the infected mice treated with albendazole and Dexa (subgroup $\mathrm{Vc}$ ), there was an insignificant decrease in the mean serum level reaching $12.90 \pm 3.25(\mathrm{P}=0.184)$. There was a significant decrease in the mean serum level of subgroup IVc and subgroup $\mathrm{Vc}$ in relation to subgroup IIIc (treated with albendazole) $(\mathrm{P}$ $=0.017)$ and $(\mathrm{P}=0.021)$ respectively. However, there was an insignificant difference between subgroups IVc (treated with albendazole and RTX) and $\mathrm{Vc}$ (treated with albendazole and Dexa) $(\mathrm{P}=0.495)$ (Fig. $8 b)$.

\section{Determination of the serum levels of iNOS by ELISA}

\section{Serum levels of iNOS determined on day 6} p.i. in subgroups (a)

The mean normal serum level of iNOSin the non-infected non-treated mice (group I) was $135.67 \pm 26.63$. The mean serum level in the infected non-treated group (subgroup IIa) showed a highly significant increase reaching $488.33 \pm 46.44(\mathrm{P}=0.001)$. In relation to subgroup (IIa), there was a significant decrease in the mean serum level of the infected mice treated with albendazole and RTX (subgroup IVa) and those treated with albendazole and Dexa (subgroup Va) as their mean level reached $346.33 \pm 57.13(\mathrm{P}=$ $0.029)$ and $382.67 \pm 46.20(\mathrm{P}=0.049)$ respectively. However, there was an insignificant increase in the mean serum level in the infected mice treated with albendazole (subgroup IIIa) as its mean level reached $500.67 \pm 27.47(\mathrm{P}=0.628)$. In addition, there was a significant decrease in the mean serum level in subgroup IVa and subgroup $\mathrm{Va}$ in relation to subgroup IIIa $(\mathrm{P}=0.012$ and 0.017). However, there was an insignificant difference in the mean serum level between subgroup IVa and subgroup Va $(\mathrm{P}=0.440)$ (Fig. 9a).

\section{Serum levels of iNOS determined on day 25} p.i. in subgroups (c)

The mean serum level in the infected nontreated group (subgroup IIb) was significantly 
increased reaching $372.33 \pm 89.5(\mathrm{P}=0.012)$. In relation to subgroup $\mathrm{IIb}$, there was an insignificant increase in the mean serum level in the infected mice treated with albendazole (subgroup IIIc) as their mean level reached $437.0 \pm 25.06(\mathrm{P}=0.134)$. However, there was a significant decrease in the mean serum level in the infected mice treated with albendazole and RTX (subgroup IVc) reaching $266.0 \pm 35.04(\mathrm{P}=0.023)$. In addition, there was a significant decrease in the mean serum level in the infected mice treated with albendazole and Dexa (subgroup $\mathrm{Vc})$ reaching $284.3 \pm 35.02(\mathrm{P}=0.049)$. There was a significant decrease in the mean serum level in subgroup IVc (treated with albendazole and RTX) in relation to subgroup IIIc (treated with albendazole) $(\mathrm{p}$ value $=$ 0.002). There was an insignificant difference between subgroups IVc and $\mathrm{Vc}$ (treated with albendazole and Dexa) $(\mathrm{P}=0.654)$ (Fig. 9b).

Trichinellosis is a zoonotic parasitic disease caused byT. spiralis and has both intestinal and tissue phases.The immune response against $T$. spiralis at the intestinal phase depends on the T-helper cells (Th). Stimulation of Th cells includes both Th1 and Th2 with initial predominance of the Th1 type and subsequent domination of $\mathrm{Th} 2$ in order to achieve protection and parasite expulsion (Ilic et al., 2012). This process is characterized by secretion of cytokines such as interleukin IL4, IL5, IL10 and IL13, as well as immunoglobulin E (Bruschi and Chiumiento, 2012).

The activity of IL4 and IL13 leads to release of TNF- $\alpha$ and INF- $\gamma$, by the activation of intestinal mucosal mast cells resulting in local inflammation (Akiho et al., 2011). Release of TNF- $\alpha$ leads to stimulation of iNOS, resulting in the production of nitric oxide (NO) which has an effect against both extracellular and intracellular parasites. The inflammatory response caused by TNF- $\alpha$ and NO enhances the development of enteropathy by $T$. spiralis (Wink et al., 2010). Albendazole is widely used in the treatment of trichinellosis with a high therapeutic index and low toxicity (Gottstein et al., 2009).

In addition, steroids are used during trichinellosis in order to decrease the inflammatory response. However, their side effects limit their use and they mainly suppress the immune response. So, they increase the parasite burden and its survival in the host tissue (Gottstein et al., 2009). Resiniferatoxin (RTX) is derived from a cactus-like plant named Euphorbia resinifera. Most of the biological actions of RTX are mediated by the transient receptor potential vanilloid 1 (TRPV1) by intial desensitizing then blocking these receptors leading to its analgesic effect (Nilius and Szallasi, 2014). It also has a potent anti-inflammatory effect by reducing the expression of cyclooxygenase- 2 $(\mathrm{COX}-2)$ and iNOS, therefore inhibiting the synthesis of both prostaglandin-E2 (PGE2) and NO (Chen et al., 2003).

In the present study, the TLC of $T$. spiralis in the muscles was performed on day 35 p.i.. In early treated subgroup (IIIb), there was a highly significant decrease in the mean total larval count of the infected mice treated with albendazole as compared to the infected nontreated group $(\mathrm{IIb})(\mathrm{P}=0.001)$ with $97.5 \%$ reduction while in late treated group (IIIc), the reduction rate was $55 \%$. These results agreed with the study of Attia et al., (2015) who used albendazole in a dose of $50 \mathrm{mg} / \mathrm{kg}$ for three successive days starting on day 3 p.i.. There was a significant decrease in TLC detected in the mice which received albendazole during the intestinal phase with efficacy of $90.9 \%(p<0.01)$.

In the present study, there was a highly significant decrease in the mean TLC in the infected mice treated with albendazole and 
RTX (200 \pm 48.99$)$ as compared with the infected control with $99 \%$ reduction. However, in the infected mice treated with albendazole and Dexa, the reduction was 95\%. Moreover, there was a significant decrease in the larval count in mice treated with albendazole and RTX than those treated with albendazole only $(P=0.002)$.

This may be explained on the basis of the possible effect of RTX on the fecundity of $T$. spiralis adults giving less larval count than was expected. Also, this could be attributed to the protective effect of RTX on the integrity of the intestinal wall.

Moreover, this agree with Munoz-Carrillo et al., (2017-a) who showed that $T$. spiralisnewborn larvae (NBL) treated with RTX had decreased infectivity which further affected the development of the $T$. spiralis life cycle in mouse infection, as RTX decreased significantly both the implantation of $T$. spiralis- NBL and the parasite burden in the muscular phase.

In the mice treated with (albendazole and Dexa), the TLC was larger than that in both albendazole treated subgroup and the subgroup treated with albendazole and RTX but with no statistically significant difference.

It can be suggested that, this is a consequence of the immunosuppressive effect of cortisone which allowed large numbers of larvae to migrate and occupy the muscles of the host.

The effect of cortisone alone as antiinflammatory drug was studied by Coker (2019) who declared that the TLC in the muscles of the cortisone-treated mice were almost twice those from the control group. These counts were not related only to the number of the adult worms but also due to the huge number of the larvae which were capable of establishing themselves in the muscles. These effects were due to the suppression of the cellular response in the intestine by cortisone. Similar results were obtained by Alvarado et al., (1996) who showed that in rats treated with betamethasone, there was an increase in the TLC as compared to the infected non-treated group. This was explained by Piekarska et al., (2010) who showed that Dexa increased the proportion of apoptotic and necrotic lymphocytes, as well as the number of larvae in the muscle tissue. The mechanism of immunosuppression by cortisone was explained by Ashwell et al., (2000) as it inhibits the expression of pro-inflammatory genes by transcription factors suppression; such as NF- $\mathrm{kB}$ and the activator protein which regulate the expression of genes encoding many inflammatory cytokines such as TNF- $\alpha$, IL- $1 \alpha$, IL- $1 \beta$, IL- 8, IFN- $\alpha$ and IFN- $\beta$.

The effect of RTX alone on T. spiralis infected mice as compared to Dexa was studied by Munoz-Carrillo et al., (2016). They showed that in the infected group treated with Dexa on day 1 p.i., there was a non-significant increase in the parasite burden compared to the infected non-treated group. In contrast, when RTX was administered on day 1 p.i., the parasite burden decreased significantly $(\mathrm{P}<0.05)$.

In the present study TLC of T. spiralis was performed on late treated subgroups, which started treatment on day 21 p.i. (G IIIc, IVc, $\mathrm{Vc}$ ). It has been found that in relation to TLC of the infected non-treated mice, there was a highly significant decrease in the mean TLC of the infected mice treated with albendazole with 55\% reduction rate, albendazole and RTX with $64 \%$ reduction rate and albendazole and Dexa with 60\%reduction rate $(P=0.001)$ with no significant difference between the three groups. 
Regarding the histopathological study performed on day 6 p.i., small intestinal sections of $T$. spiralis infected non-treated mice revealed edema and elongation of the villous core with severe inflammatory cellular infiltrate. The infiltrate was in the form of lymphocytes, eosinophils and neutrophils giving a mean inflammatory score of $5.40 \pm$ 0.55. In addition, there were goblet cell hyperplasia, high mitotic activity and hyperplasia of the payer's patches.

In the present study, as regard to mice treated with albendazole only, there were moderately elongated villi, moderate edema and inflammatory cellular infiltrate with a mean inflammatory score of $3.20 \pm 0.84(\mathrm{P}=$ 0.001). However, in the infected mice treated with albendazole and RTX, there was mild inflammation and even there was almost normal intestinal epithelium in some mice with a mean inflammatory score of $0.80 \pm$ $0.45(\mathrm{P}=0.001)$. Also, in the infected mice treated with albendazole and Dexa, there were mild inflammatory cellular infiltrate with lymphoid hyperplasia, shortening of the villi and mild edema with a mean inflammatory score of $1.40 \pm 0.55(\mathrm{P}=0.001)$.

Similar results were obtained by MunozCarrillo et al., (2016) who found a marked reduction in the intestinal pathology in RTX and Dexa treated subgroups on day 1 p.i. with a dose $(20 \mu \mathrm{g} / \mathrm{kg})$ and $(1 \mathrm{mg} / \mathrm{kg})$ respectively. There was a reduction in the intestinal crypts hyperplasia and reconstitution of the intestinal villi ( $\mathrm{P}<0.05$ and $\mathrm{P}<0.01$ respectively). However, adult females of $T$. spiralis were still observed in both duodenum and jejunum. In addition, the infected groups treated with RTX and Dexa with the same doses on day 7 p.i. did not show any intestinal pathology, the intestine was almost normal.

In the current study, the histopathological examination of muscle sections of $T$. spiralis infected non-treated mice on day 35 p.i., revealed multiple encapsulated larvae surrounded by severe inflammatory cellular infiltrate between the muscle fibers and around the encapsulated larvae. The infiltrate was in the form of plasma cells, lymphocytes, macrophages and neutrophils giving a mean inflammatory score of $5.60 \pm 0.55$. There was loss of the myofibrils.

Regarding mice treated with albendazole only, there was a less number of encapsulated larvae surrounded by moderate inflammatory cellular infiltrate in the early treated subgroups (b)with a mean inflammatory score of $2.80 \pm 0.84(\mathrm{P}=0.001)$. On the other hand El-Gendy et al., (2015) detected mild inflammatory cellular infilteration around the encapsulated muscle larvae five weeks p.i. in $T$. spiralis infected mice treated with albendazole.

As regards the infected mice treated with albendazole and RTX showed mild inflammatory cells and minimal amount of larvae and some showed absent larvae with normal striation with a mean inflammatory score of $0.80 \pm 0.84(\mathrm{P}=0.001)$. However in the infected mice treated with albendazole and Dexa, there were nurse cells with mild to moderate inflammatory cellular infiltrate giving a mean inflammatory score of $2.40 \pm$ $0.89(\mathrm{P}=0.001)$.

In the late treated subgroups (c), the infected mice treated with albendazole only showed moderate to severe inflammatory cellular infiltrate, remnants of the larvae and hyaline degeneration of some nurse cells with a mean inflammatory score of $4.20 \pm 0.84(\mathrm{P}=$ 0.008). In the infected mice treated with albendazole and RTX, mild to moderate inflammatory infiltrate, remnants of the larva and hyaline degeneration of the nurse cells were detected giving a mean inflammatory score of $(1.60 \pm 0.55)(\mathrm{P}=0.001)$. Also, in the 
infected mice treated with albendazole and Dexa, there was mild to moderate inflammatory cellular infiltrate around the encapsulated larvae giving a mean inflammatory score of $2.40 \pm 0.89(\mathrm{P}=$ 0.001).

IFN- $\gamma$ is a cytokine that forms an important part of both innate and adaptive immunity in $T$. spiralis infection. It has important protective effects against the newly born larvae that in turn may restrict the number of larvae entering the blood circulation (Helmby and Grencis, 2003).

Moreover, IFN- $\gamma$ increases the development and differentiation of Th1 cells, induces the expression of iNOS and regulates the production of pro-inflammatory cytokines, such as TNF- $\alpha$. In the immune response against $T$. spiralis infection, IFN- $\gamma$ has a key role in the pathogenesis of inflammatory diseases, as it participates in the activation of a cascade of pro-inflammatory cytokines, especially IL-1 $\beta$, IL-6 and IL-8 (Muhl and Pfeilschifter, 2003).

In the current study, the mean serum levels of IFN- $\gamma$ in both early and late treated subgroups were determined on days 6 and 25 p.i. respectively. The results showed a significant increase in the mean serum level of IFN- $\gamma$ in the infected non-treated group $(\mathrm{P}<0.05)$. These results were in agreement with the results of many studies. Bakir et al., (2017) showed a significant difference between the levels of IFN- $\gamma$ in the infected non-treated group through days of infection with a significant peak of expression on day 5 p.i.. Chen et al., (2013) showed that there was a significant increase in the serum levels of IFN- $\gamma$ during the early phase of infection especially on day 7 p.i.. Stolley and Campbell (2016) detected an increase about 2.5 fold in the IFN- $\gamma$ expression at the mRNA level. In the serum, IFN- $\gamma$ increased also during the early days of infection.
In the present work, there was an insignificant increase in the mean serum IFN- $\gamma$ levels of the infected mice treated with albendazole alone in comparison to the infected nontreated mice $(\mathrm{P}>0.05)$. This was explained by $\mathrm{Du}$ et al., (2003) who declared that albendazole is a benzimidazole derivative that inhibits microtubule synthesis in the parasite and modifies the cytokine responses changing the immune response from Th2 to Th1 dominance and increases IFN- $\gamma$ levels. On the other hand, in the present study, there was a significant decrease in the mean serum levels of IFN- $\gamma$ in the infected mice treated with (albendazole and RTX) $(\mathrm{P}<0.05)$. There was no significant difference in the mean serum level between the subgroup treated with (albendazole and RTX) and the subgroup treated with (albendazole and Dexa) $(\mathrm{P}>$ 0.05).In agreement with these results, MunozCarrillo et al., (2017-a) compared between the effect of RTX and cortisone on the intestinal phase of $T$. spiralis in mice. They detected that in the RTX treated group with a dose 20 $\mu \mathrm{g} / \mathrm{kg}$ for two doses on day 1 and 3 p.i., it was observed that the serum levels of IFN- $\gamma$ were decreased significantly $(\mathrm{P}<0.05)$ to a level similar to that of the groups treated with Dexa $(1 \mathrm{mg} / \mathrm{kg})$ at the same time. The results of the present study concerning the marked decrease in the serum level of IFN- $\gamma$ in RTX treated groups declared the improvement of the histopathological changes in the small intestine and the muscle by modulation of the immune response with decrease of other proinflammatory cytokines involved in the inflammatory process as well as the decrease in iNOS level with decrease in oxidative stress (Munoz-Carrillo et al., 2017).

NO is produced from arginine by the action of iNOS produced from activated T-helper cells. It is one of the most important secretory products of macrophages that participate in the host defense function. It destroys and suppresses many parasites (Ascenzi and Gradoni, 2002). 


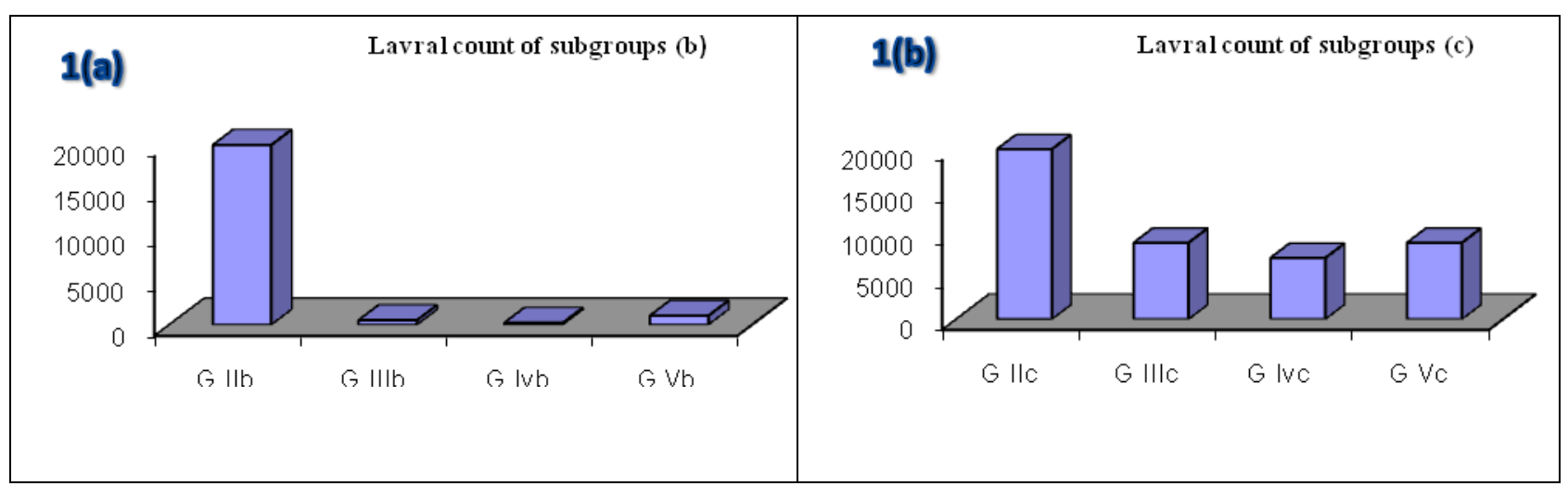

Fig. (1a): Mean values of TLC of T. spiralis in the skeletal muscles of mice in subgroups (b) on day 35 p.i. and Fig. (1b): Mean values of TLC of T. spiralis in the skeletal muscles of subgroups (c) on day 35 p.i.

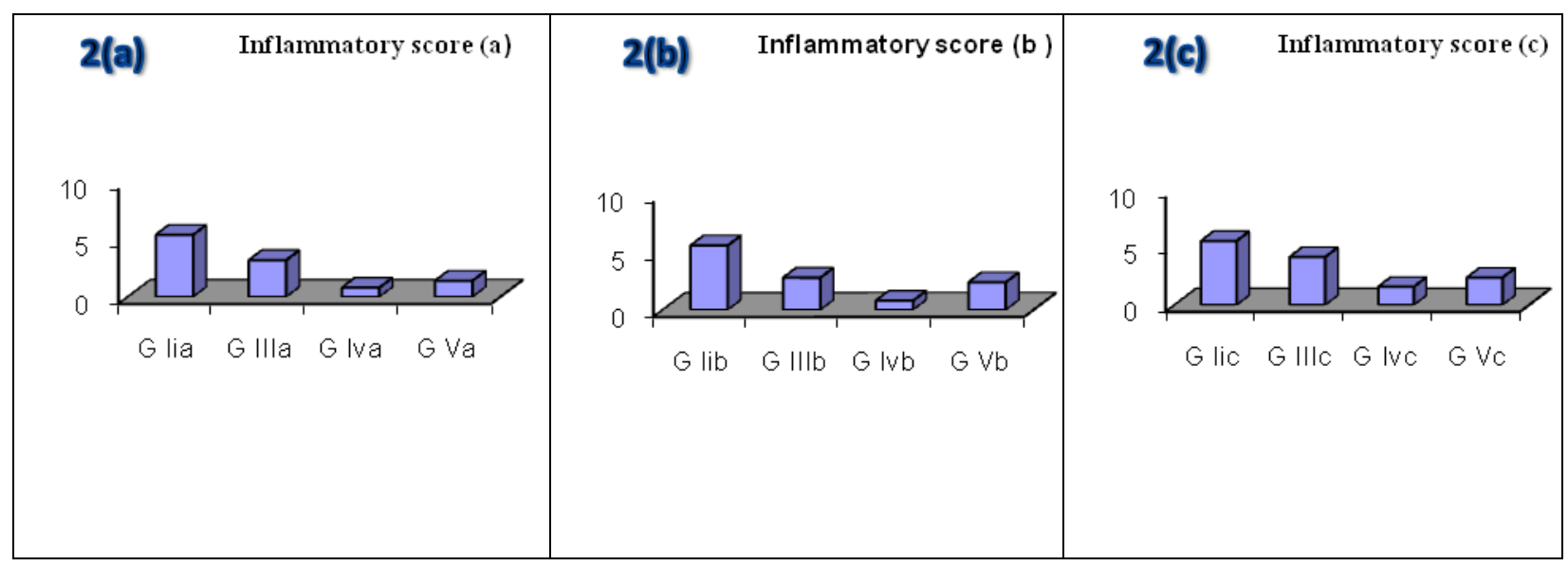

Fig. (2a): Mean inflammatory score in the small intestinal section for subgroups (a) on day 6 p.i., Fig. (2b): Mean inflammatory score in in the skeletal muscle section for subgroups (b) on day 35 p.i. and Fig. (2c): Mean inflammatory score in in the skeletal muscle section for subgroups (c) on day 35 p.i.

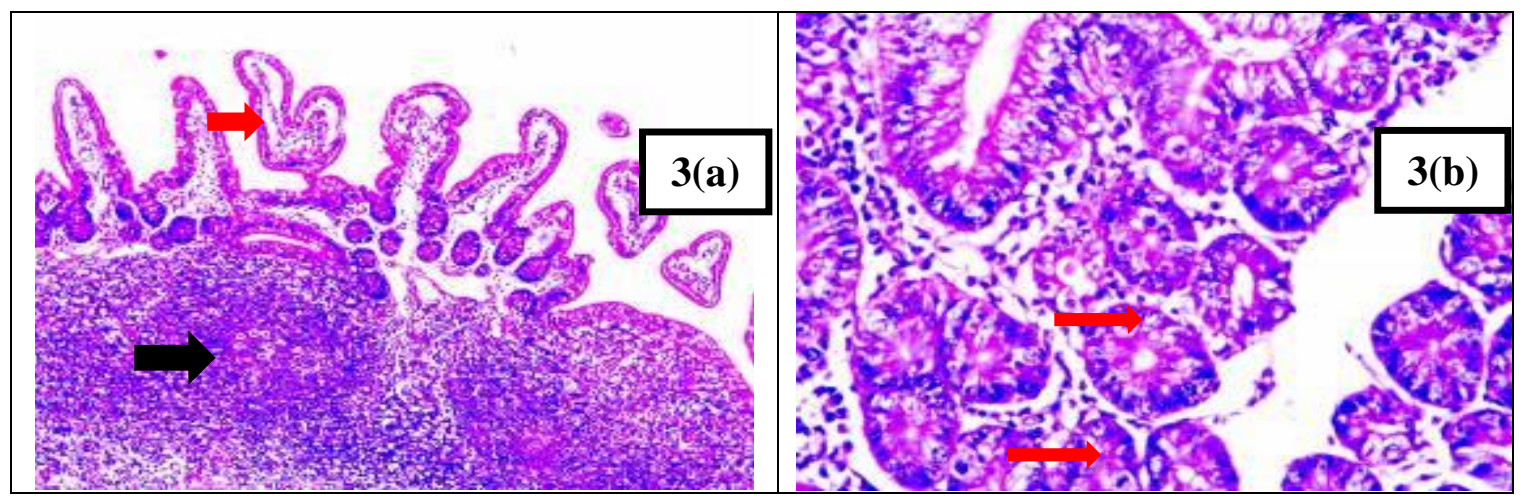

Fig. (3a): Small intestinal section of T. spiralis infected non-treated mouse (subgroup IIa) 6 days p.i. showing edema of the villous core (red arrow) with severe inflammatory cellular infiltrate (black arrow) (H\&E X 40) and Fig. (3b): Small intestinal section of T. spiralis infected nontreated mouse (subgroup IIa) 6 days p.i. showing high mitotic activity with two mitosis (red arrows) (H\&E X 400) 


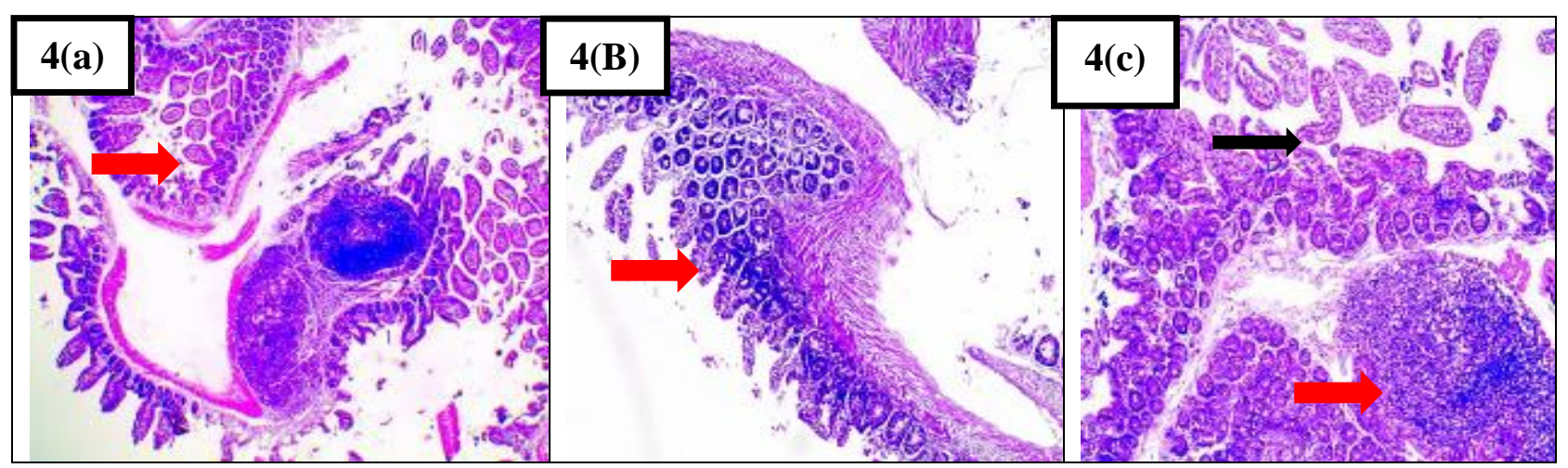

Fig. (4a): Small intestinal section of T. spiralis infected mouse treated with albendazole (subgroup IIIa) 6 days p.i. showing moderately elongated villi, moderate edema and inflammatory cellular infiltrate (H\&E X 40), Fig. (4b): Small intestinal section of $T$. spiralis infected mouse treated with albendazole and RTX (subgroup IVa) 6 days p.i. showing almost normal intestinal epithelium (arrow) (H\&E X 100) and Fig. (4c): Small intestinal section of T. spiralis infected mouse treated with albendazole and Dexa (subgroup Va) 6 days p.i. showing lymphoid hyperplasia (red arrow), shortening of the villi with no edema and mild inflammatory cellular infiltrate (black arrow) (H\&E X 100).

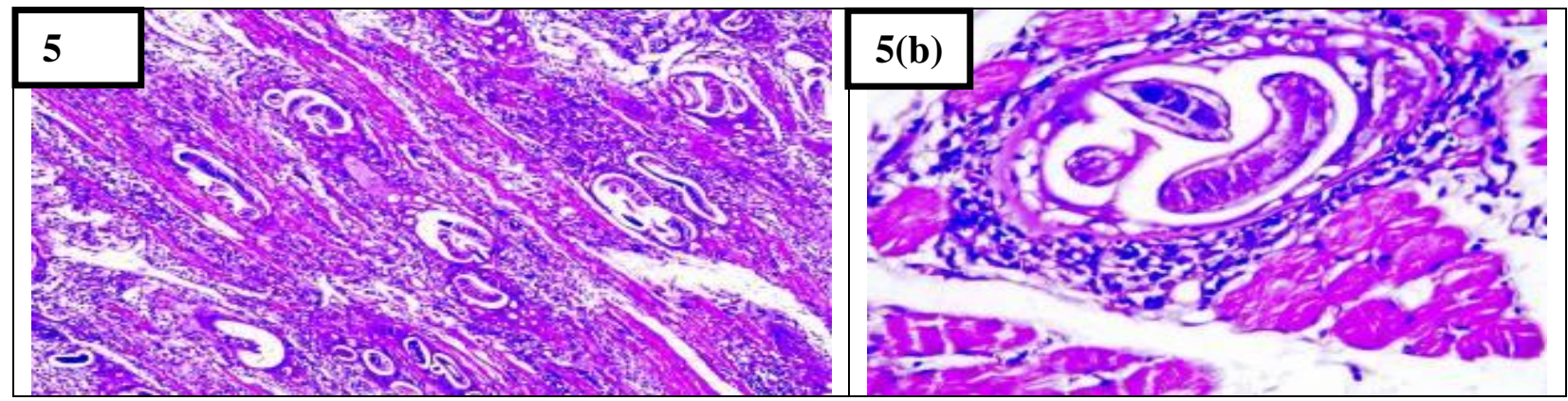

Fig. (5a): Muscle section of T. spiralis infected non-treated mouse (subgroup IIb) 35 days p.i. showing severe inflammatory cellular infiltrate between the muscle fibers around the encapsulated larvae with loss of the myofibrils (H\&E X 100) and Fig. (5b): Muscle section of T. spiralis infected non-treated mouse (subgroup IIb) 35 days p.i. showing nurse cell containing encapsulated larva surrounded by chronic inflammatory cells as plasma cells, lymphocytes, macrophages and neutrophils (H\&E X 400).

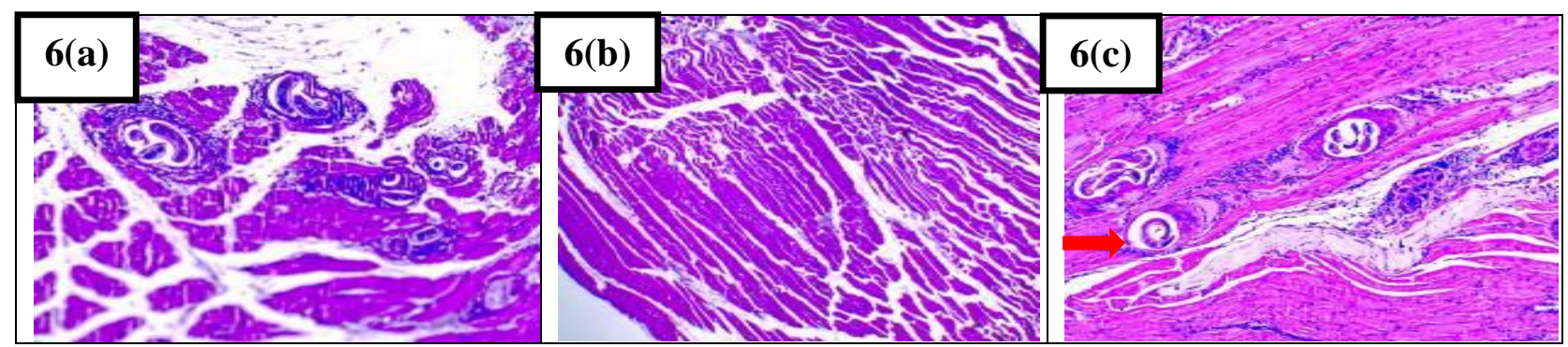

Fig. (6a): Muscle section of T. spiralis infected mouse treated with albendazole (subgroup IIIb) 35 days p.i. showing less number of encapsulated larvae with moderate inflammatory cellular infiltrate (H\&E X 100), Fig. (6b): Muscle section of $T$. spiralis infected mouse treated with albendazole and RTX (subgroup IVb) 35 days p.i. showing absent inflammatory cells and larvae with normal striation (H\&E X 40) and Fig. (6c): Muscle section of $T$. spiralis infected mouse treated with albendazole and Dexa (subgroup $\mathrm{Vb}$ ) 35 days p.i. showing nurse cells with moderate inflammatory cellular infiltrate (red arrow) (H\&E X 100). 


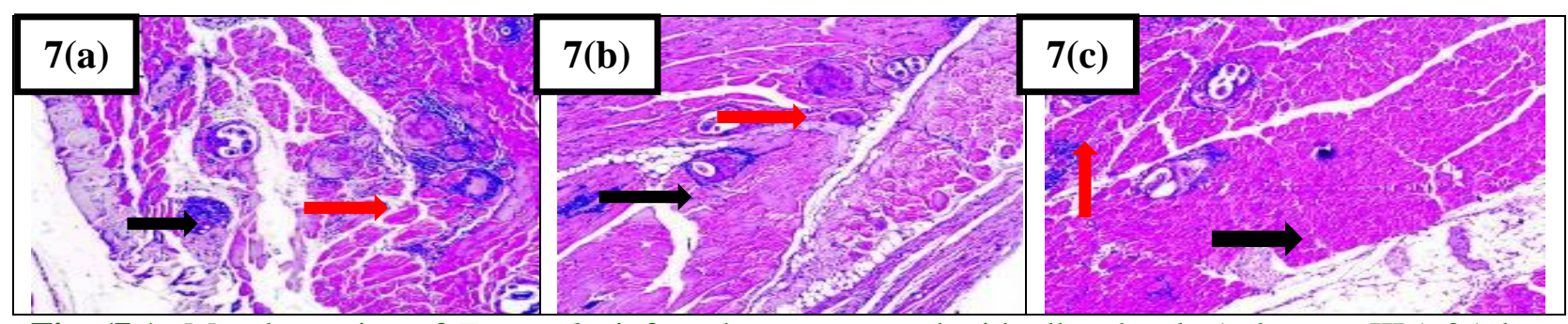

Fig. (7a): Muscle section of T. spiralis infected mouse treated with albendazole (subgroup IIIc) 35 days p.i. showing moderate inflammatory cellular infiltrate, remnants of the larvae (black arrow) and hyaline degeneration of some nurse cells (red arrow) (H\&E X 100), Fig. (7b): Muscle section of T. spiralis infected mouse treated with albendazole and RTX (subgroup IVc) 35 days p.i. showing mild inflammatory cellular infiltrate, remnants of the larva (black arrow) and hyaline degeneration of the nurse cells (red arrow) (H\&E X 100) and Fig. (7c): Muscle section of T. spiralis infected treated mouse with albendazole and Dexa (subgroup Vc) 35 days p.i. showing encapsulated larvae with moderate inflammatory cellular infiltrate (red arrow) and calcification (black arrow) (H\&E X 100).

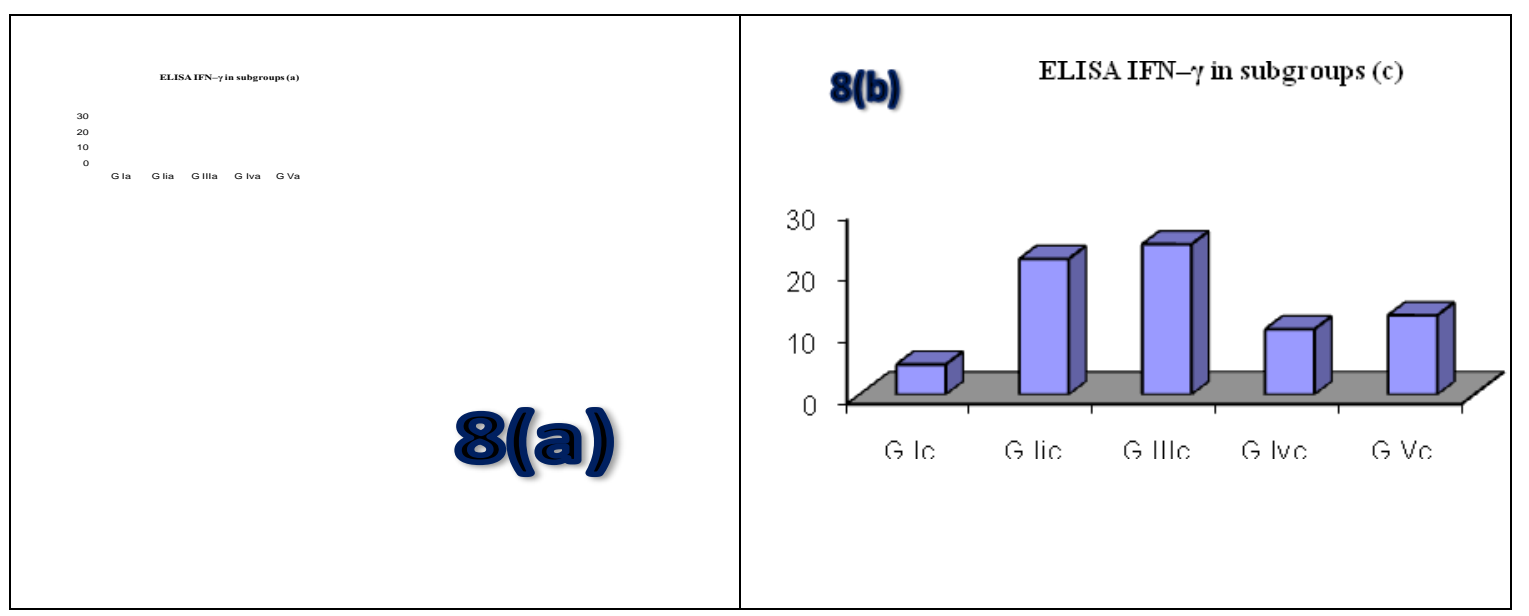

Fig. (8a): The mean values of the serum level of IFN- $\gamma$ in subgroups (a) on day 6 p.i. and Fig. (8b): The mean values of the serum levels of IFN- $\gamma$ in subgroups (c) on day 25 p.i.

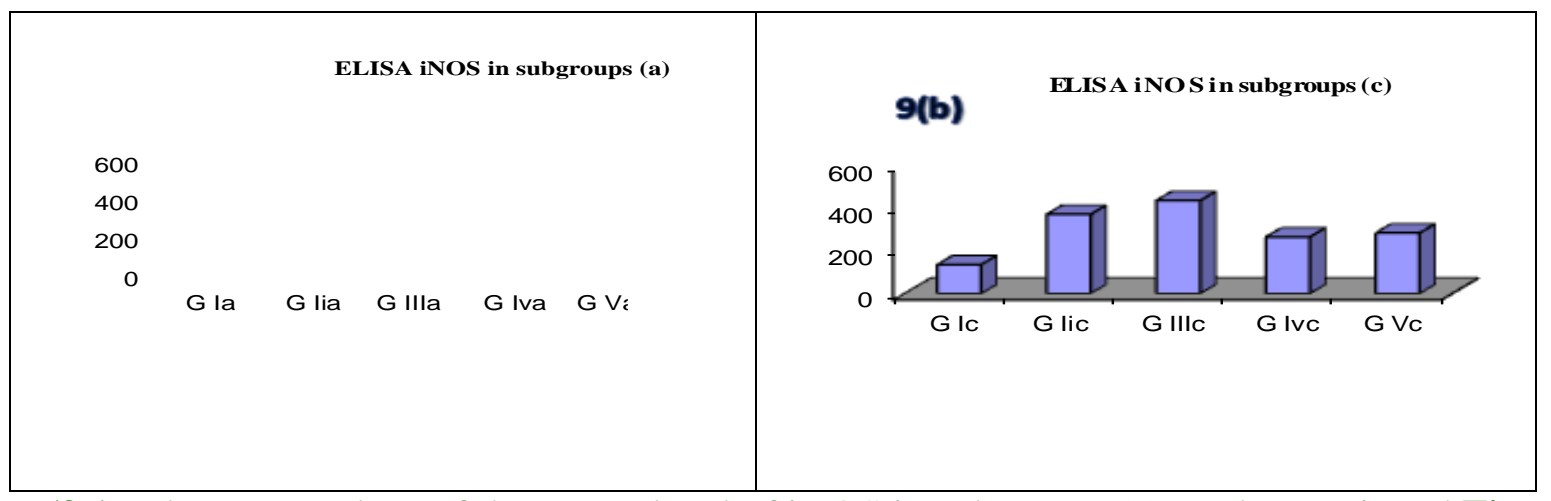

Fig. (9a): The mean values of the serum level of iNOS in subgroups (a) on day 6 p.i. and Fig.

(9b): The mean values of the serum level of iNOS in subgroups (c) on day 25 p.i.

During the early phase of $T$. spiralis infection, NO has a minor role in the adult expulsion; however, it plays a vital role in the intestinal pathology. Supporting this hypothesis, it was found that in iNOS-deficient mice there was no evidence of villus atrophy with less crypt hyperplasia and lower number of mitotic figures per crypt (Lawrence, et al., 2000). 
Several structural and biochemical changes caused by oxygen and nitrogen free radicals occur in muscles at the late phase of infection. These changes are caused by both the host and the parasite (Boczon et al., 2004). These free radicals combine with NO forming peroxynitrate, which leads to injury or death of the muscle fibers (Boczon and Wargin, 2000). It was found that inhibition of iNOS during multiple infections including viruses, bacteria and protozoan parasites could greatly improve the survival despite an increase in pathogen numbers (Karupiah et al., 1998).

In the current study, the mean serum levels of iNOS were determined in both the early and late treated subgroups. In the infected nontreated group, there was a highly significant increase in its mean serum level $(\mathrm{P}=0.001)$. Attia et al., (2015) showed similar results. They stated that iNOS expression on day 7 p.i. was highest in the inflammatory cells infiltrating the intestine of the infected nontreated group. The level was higher than the albendazole treated one.

Also, it was found that there was a highly significant increase in the NO serum levels (about 2-fold on day 14p.i.) and in the NO release from the peritoneal macrophages in infected mice (maximal about 3-fold on day 21p.i.) in comparison with the healthy control (Wandurska-Nowak and Wisniewska, 2002). The present findings (regarding the mean serum levels of iNOS in the infected mice treated with albendazole alone) showed that there was an insignificant increase in its mean value $(\mathrm{P}>0.05)$. This came in accordance with Zeromski et al., (2005) who showed that strong iNOS expression could be detected in the inflammatory cells infiltrating and surrounding the encapsulated $T$. spiralis larvae in the infected muscles after albendazole treatment. These results confirmed previous biochemical data which reported that albendazole treatment during experimental trichinellosis resulted in the stimulation of iNOS expression (Fathy, 2011). Similarly, Boczon et al., (2004) found that during the muscular phase of infection the iNOS expression in the infected non-treated mice increased from day 21 p.i. in nearly all inflammatory cells between the muscle fibers and around the encysted larvae. Also, there was a significant increase in the iNOS expression detected in albendazole treated groups in comparison with the infected nontreated one. In the present study, regarding the infected mice treated with (albendazole and RTX) and those treated with (albendazole and Dexa), there was a significant decrease in the mean serum level of iNOS in relation to the infected non-treated group $(\mathrm{P}<0.05)$. Meanwhile, there was no significant difference in the mean serum levels of iNOS between the infected mice treated with albendazole and RTX and those treated with albendazole and Dexa ( $>>0.05)$.In agreement with the results of the present work, Munoz-Carrillo et al., (2016) found that when RTX $(20 \mu \mathrm{g} / \mathrm{kg})$ was administered on day 1 and 7 p.i. in T. spiralis infected rats, the serum levels of NO detected 90 minutes after treatment decreased significantly when compared to the infected non-treated group ( $\mathrm{P}$ $<0.01)$. Also, there was a significant decrease in the levels of serum NO in the infected group treated with Dexa $(1 \mathrm{mg} / \mathrm{kg})$ on day 1 and 7 p.i.. In addition, Ueda et al., (2008) found that RTX inhibited the expression of iNOS in the macrophages stimulated by lipopolysaccharide and IFN- $\gamma$ thus resulting in a decrease in NO.The current results of serum level of iNOS supported the hypothesis that the production of $\mathrm{NO}$ is associated with the development of the intestinal pathology during the intestinal phase of infection. Treatment with both RTX and Dexa produced a decrease in NO, along with a reduction in the hyperplasia of the intestinal crypts and the reconstitution of the intestinal villi. 
From the present study, it could be concluded that RTX improved the inflammatory process in the small intestine and in the muscles as evidenced by the histopathological examination with death of many implanted larvae in the muscles. Moreover, RTX led to marked decrease in both IFN- $\gamma$ and NO in the early treated groups indicating that RTX induced immune modulation as well as reduction of the oxidative stress especially in intestinal phase thus limiting the inflammatory process in the small intestine and in the muscles. Regarding the parasite burden, RTX showed marked decrease in TLC in the striated muscles especially in early treated group with insignificant decrease in adult worm count in the small intestine. This could be explained by the action of RTX that decreased the implantation of the larvae in the muscles. On the other hand, cortisone -treated groups showed significant increase in the number of TLC as compared with RTX treated one as RTX modulated the production of pro-inflammatory cytokines while cortisone suppressed them. This indicated the immunosuppressive effect of cortisone which favored the implantation of the parasite. From the previous results, it can be concluded that resiniferatoxin had a marked antiinflammatory effect when used as an adjuvant with albendazole in the treatment of $T$. spiralis infection as a model of both intestinal and tissue parasite especially when used in the early stage of infection. This was showed by the marked decrease in the inflammatory changes in the small intestine as well as in the skeletal muscles.The usage of RTX in conjunction with albendazole showed a marked decrease in the parasitic load in the striated muscles. In albendazole and cortisone treated groups, there was marked antiinflammatory effect but with significant increase in the total larval count in the muscles as compared to RTX treated groups due to its immune suppressive effect. Resiniferatoxin modulated the immune response against $T$. spiralis and decreased the oxidative stress especially in the early phase of infection as evidenced by the marked decrease in the serum level of IFN- $\gamma$ and iNOS.

\section{References}

Akiho, H., Ihara, E., Motomura, Y. and Nakamura, K. (2011): Cytokine-induced alterations of gastrointestinal motility in gastrointestinal disorders. World J. Gastrointest. Pathophysiol.; 2: 72-81.

Alvarado, R.M., Meza, L.E. and Garcia, M.E. (1996): Hormonal effect on the parasite load in the infection by $T$. spiralis of a murine experimental model. Trichinellosis. In: Wakelin OP, ed. 9th International Conference Trichinellosis (ICT); 9:107- 114.

Ascenzi, P. and Gradoni, L. (2002): Nitric oxide limits parasite development in vectors and in invertebrate intermediate hosts. IUMBM Life; 53: 121-123.

Ashwell, J.D., Lu, F.W. and Vacchio, M.S. (2000): Anti-inflammatory treatment in trichinellosis. Glucocorticoids function. Annu. Rev. Immunol.; 18: 309-345.

Attia, $\quad$ R.A., Mahmoud, A.E., Farrag, H.M., Makboul, R., Mohamed, M.E. and Ibraheim, Z. (2015): Effect of myrrh and thyme on Trichinella spiralis enteral and parenteral phases with inducible nitric oxide expression in mice. Mem. Inst. Oswaldo. Cruz.; 110 (8):1035-1041.

Bakir, H.Y., Attia, R.A.H., Mahmoud, A.E. and Ibraheim, Z. (2017): M-RNA Gene Expression of INF- $\gamma$ and IL-10 during Intestinal Phase of Trichinellaspiralis after Myrrh and Albendazole Treatment. Iran J. Parasitol.; 12 (2): 188-195.

Boczon, K. and Wargin, B. (2000): Inducible nitric oxide synthase in the muscles of Trichinella spp. infected mice treated with glucocorticoid methylprednisolone. Comp. Parasitol.; 67: 230-235.

Boczon, K., Wandurska-Nowak, E., Wierzbicki, A., Frydrychowicz, M., Mozer-Lisewska, I. and Zeromski, J. (2004): mRNA expression and immunohistochemical localization of 
inducible nitric oxide synthase (NOS-2) in the muscular niche of Trichinella spiralis. Folia. Histochem. Cytobiol.; 42: 209-213.

Bruschi, F. and Chiumiento, L. (2012): Immunomodulation in trichinellosis: does Trichinella really escape the host immune system? Endocr. Metab. Immune Disord. Drug Targets; 12:4-15.

Chen, C.W., Lee, S.T., Wu, W.T., Fu, W.M., Ho, F.M. and Lin, W.W. (2003): Signal transduction for inhibition of inducible nitric oxide synthase and cyclooxygenase- 2 induction by capsaicin and related analogs in macrophages. Br. J. Pharmacol.; 140:1077-1087.

Chen, Y., Huang, B., Huang, S., Yu, X., Li, Y. and Song, W. (2013): Coinfection with Clonorchis sinensis modulates murine host response against Trichinella spiralis infection. Parasitol. Res.; 112: 3167-3179. Coker CM (2019) Effects of Cortisone on Trichinellaspiralis Infections in NonImmunized Mice.J Parasitol 41(5): 498504.

Du, W.Y., Liao, J.W., Fan, C.K. and Su, K.E. (2003): Combined treatment with interleukin-12 and mebendazole lessens the severity of experimental eosinophilic meningitis caused by Angiostrongylus cantonensis in ICR mice. Infection and Immunity; 71: 3947-3953.

El-Gendy, D.I.M., El Kowrany, S.I, Eid, M.M., Sallam, F.A.A. and Othman, A.A. (2015): The Effect of Beta Glucan on the Therapeutic Outcome of Experimental Trichinellosis. M.D. Thesis. Parasitology Department, Faculty of Medicine, Tanta University, Egypt.

El-Kowrany, S.I., El Ghaffar, A.E.A., Shoheib, Z.S., Mady, R.F. and Gamea, G.A.M. (2019):Evaluation of nitazoxanide as a novel drug for the treatment of acute and chronic toxoplasmosis. Acta. Trop.; 195:145-154.

Fathy, F.M. (2011): Effect of mirazid (Commiphora molmol) on experimental giardiasis. J. Egypt. Soc. Parasitol.; 41: 155-177.

Gottstein, B., Pozio, E. and Nockler, K. (2009): Epidemiology, diagnosis, treatment and control of trichinellosis. Clin. Microbiol.
Rev., 22 (1): 127-145.

Helmby, H. and Grencis, R.K. (2003): Contrasting roles for IL-10 in protective immunity to different life cycle stages of intestinal nematode parasites. Eur. J. Immunol.; 33(9):2382-2390.

Ilic, N., Gruden-Movsesijan, A. and SofronicMilosavljevic, L. (2012): Trichinellaspiralis: shaping the immune response. Immunol. Res.; 52: 111-119.

Karupiah, G., Chen, J.H., Mahalingam, S., Nathan, C.F. and MacMicking, J.D. (1998): Rapid interferon $\gamma$-dependent clearance of influenza $A$ virus and protection from consolidating pneumonitis in nitric oxide synthase 2-deficient mice. J. Exp. Med.; 188:15-41.

Lawrence, C., Paterson, J., Wei, X., Liew, F., Garsiede, P. and Kennedy, M. (2000): Nitric oxide mediates intestinal pathology but not immune expulsion during Trichinella spiralis infection in mice. J. Immunol.; 164: 4229-4234.

Li, R.H., Pei, Y.J., Li, Q.C., Huo, J., Ding, Y. and Yin, G.R. (2012): Efficacy of albendazole orally administered at different dosages against Trichinella spiralis encapsulated larvae in mice. Chinese J. Parasitol. and Parasit. Dis.; 30(3):184-188.

Ueda, K., Tsuji, F. and Hirata, T. (2008): Preventive effect of TRPV1 agonists capsaicin and resiniferatoxin on ischemia/ reperfusion-induced renal injury in rats. $\mathrm{J}$. Cardiovasc. Pharmacol.; 51:513- 520.

Monib, M.E.M., Shaheen, M.S., Galal, L.A. and Farrag, H.M. (2010): Role of T. spiralis adult and larval antigens in immune modulation of nitric oxide (NO) in intestinal and muscular phase of trichinellosis. Assiut Medical Journal; 34:147-158.

Muhl, H. and Pfeilschifter, J. (2003): Anti-inflammatory properties of pro-inflammatory interferon- $\gamma$. Int. Immunopharmacol.; 3: 1247- 1255.

Munoz-Carrillo, J.L., Contreras-Cordero, J.F., Munoz-Lopez, J.L., Maldonado- Tapia, C.H., Munoz-Escobedo, J.J. and MorenoGarcia, M.A. (2017): Resiniferatoxin modulates the Th1 immune response and protects the host during intestinal nematode 
infection. Parasite Immunol.; 39:1-16.

Munoz-Carrillo, J.L., Munoz-Escobedo, J.J., Maldonado-Tapia, C.H., ChavezRuvalcaba, F. and Moreno-Garcia, M.A. (2016): Resiniferatoxin lowers TNF- $\alpha$, NO and PGE2 in the intestinal phase and the parasite burden in the muscular phase of $T$. spiralis infection. Parasite Immunol.; 39: 114.

Nassef, N.E., El-Sobky, M.M. and Afifi, A.F. (2010): Worm and larval burden, histopathological and ultrastructural evaluation of $T$. spiralis vaccination using crude worms and /or larvae antigens: experimental studies. Parasitologists United Journal; 3: 27-38.

Nilius, B. and Szallasi, A. (2014): Transient receptor potential channels as drug targets: from the science of basic research to the art of medicine.Pharmacol. Rev., 66:676-814.

Piekarska, J., Szczypka, M., Michalski, A., Obminska-Mrukowicz, B. and Gorczykowski, M. (2010): The effect of immunomodulating drugs on the percentage of apoptotic and necrotic lymphocytes in inflammatory infiltrations in the muscle tissue of mice infected with Trichinella spiralis. Pol. J. Vet. Sci.; 13:233-240.

Shalaby, M.A., Moghazy, F.M., Shalaby, H.A. and Naser, S.M. (2010): Effect of methanolic extract of Balanites egyptiaca fruits on enteral and parenteral stages of Trichinella spiralis in rats. Parasitol. Res.; 107: 17-25.

Sofronic-Milosavljevic, L., Ilic, N. and GrudenMovsesijan, A. (2017): Trichinella. In: Laboratory Models for Foodborne Infections. D. Liu, ed. (Boca Raton FL: CRC Press); pp. 793-808.

Stolley, J.M. and Campbell, D.J. (2016): A 33D1C dendritic cell/autoreactive CD4C T cell circuit maintains IL-2-dependent regulatory $\mathrm{T}$ cells in the spleen. $\mathrm{J}$. Immunol.; 197:2635-2645. Sun H, Yang T and $\mathrm{Li}$ Q (2012) Dexamethasone and vitamin B12 synergistically promote peripheral nerve regeneration in rats by upregulating the expression of brainderived neurotrophic factor Arch Med Sci (5): 924- 930 .

Ueda, K., Tsuji, F. and Hirata, T. (2008): Preventive effect of TRPV1 agonists capsaicin and resiniferatoxin on ischemia/ reperfusion-induced renal injury in rats. $\mathrm{J}$. Cardiovasc. Pharmacol.; 51:513- 520.

Wandurska-Nowak, E. and Wisniewska, J. (2002): Release of nitric oxide during experimental trichinellosis in mice. Parasitol. Res.; 88: 708-711.

Wink, D.A., Hines, H.B. and Cheng, R.Y. (2010): Nitric oxide and redox mechanisms in the immune response. J. Leukoc. Biol.; 89:873891.

Wranicz, M.J., Gustowska, L., Gabryel, P., Kucharska, E. and Cabaj, W. (1998): Trichinella spiralis: induction of the basophilic transformation of muscle cells by synchronous newborn larvae. Parasitol. Res.; 84:403-407.

Wu, C.S., Wu, P.H., Fang, A.H. and Lan, C.C. (2012): FK506 inhibits the enhancing effects of transforming growth factor (TGF)-beta1 on collagen expression and TGF-beta/Smad signalling in keloid fibroblasts: implication for new therapeutic approach. Br. J. Dermatol.; 167:532-541.

Zeromski, J., Boczoń, K., Wandurska-Nowak, E. and Mozer-Lisewska, I. (2005): Effect of aminoguanidine and albendazole on inducible nitric oxide synthase (iNOS) activity in $T$. spiralis-infected mice muscles. Folia. Histochem. Cytobiol.; 43: 157-159.

\section{How to cite this article:}

Doaa A.A. Balaha, Howaida I. H. Ismail, Omnia M. K. Risk and Ghada A. M. Gamea. 2020. Effect of Resiniferatoxin as an Anti-Inflammatory Drug on Experimental Trichinellosis. Int.J.Curr.Microbiol.App.Sci. 9(07): 2906-2922. doi: https://doi.org/10.20546/ijcmas.2020.907.343 